\title{
Comparison of the risk of microbiological contamination between samples of breast milk obtained at home and at a healthcare facility
}

\author{
Vera Vanina Serra, M.D., ${ }^{a}$ Sergio Teves, M.D., ${ }^{b}$ Agustina López de Volder, M.D., \\ Fabiana Ossorio, M.D., ${ }^{c}$ Nora Aguilar, R.N., ${ }^{a}$ and Marcelo Armadans, M.D. ${ }^{a}$
}

\begin{abstract}
Introduction. Breast milk is the best food for preterm infants. Due to their inadequate suction-swallowing action, the administration of expressed breast milk should be done with an orogastric tube. There is little information available regarding the microbiological safety of expressed breast milk.

The aim of this article was to evaluate if there were any differences regarding the contamination of breast milk obtained at a healthcare facility versus at home.

Methods. Cross-sectional study that analyzed pairs of breast milk samples (one obtained at home and the other one at a healthcare facility, the same day) from mothers of hospitalized newborn infants with a gestational age $\leq 35$ weeks. Samples with over $10^{5} \mathrm{CFU} / \mathrm{mL}$ of mesophilic aerobic bacteria, or with the presence of Escherichia coli, Staphylococcus aureus, Streptococcus faecalis, enterobacterias, Pseudomonas, Salmonella, fungi, and yeast were considered contaminated. Results. A total of 280 breast milk samples (140 pairs) from 53 mothers were analyzed; 139 samples ( $49.6 \%$; 95\% CI: 43.6 to 55.6$)$ were contaminated; contamination was significantly more frequent in the samples obtained at home than in those obtained at a healthcare facility (59.6\% versus $39.6 \% ; p=0.0008$; OR $2.25 ; 95 \%$ IC: 1.36 to 3.7$)$.

Conclusion. Half of the breast milk samples had bacterial growth, which was more frequent in the samples obtained at home than those obtained at a healthcare facility.

Key words: breast milk, nutrition, newborn infant, preterm baby.
\end{abstract}

http:/ /dx.doi.org/10.5546/aap.2013.115

\section{INTRODUCTION}

Breast milk is considered the best food for preterm newborn infants, not only for its nutritional value but also for its capacity to provide protection from infections. ${ }^{1,2}$ Part of this protective effect would be given by the natural microflora present in mi$1 \mathrm{k}$, an important factor in the development and composition of the newborn infant's intestinal microflora. Staphylococci (epidermidis, hominis and capitis), streptococci (salivarius, mitis, parasanguis and peroris), lactobacilli (gasseri, rhamnosus, acidophilus, plantarum and fermentum) and enterococci (faecium) are bacteria commonly isolated in breast milk that can be considered part of the natural flora instead of contaminating microorganisms. These bacteria have a protective action against other microorganisms potentially harmful for the preterm infant. ${ }^{3}$

The importance of feeding breast milk to preterm infants has resulted in its manipulation. Expressed milk should be given via an orogastric tube because premature infants' suction-swallowing action is usually inadequate. ${ }^{4}$

Despite the enormous popularity of this practice, there is little information about the microbiological safe preparation of expressed breast milk. By and large, less than $10^{5} \mathrm{CFU} / \mathrm{mL}$ of mesophilic aerobic bacteria, ,,6 with a total count of enterobacteria lower than $10 \mathrm{CFU} / \mathrm{mL}$ is considered bacteriologically acceptable. The presence of pathogenic bacteria such as Escherichia coli, Staphylococcus aureus, Streptococcus faecalis, Enterobacter sakazakii, ( $\beta$-hemolytic) Streptococcus pyogenes, species of Pseudomonas, Proteus and Salmonellais considered unacceptable. The presence of fungi and yeast would indicate unsatisfactory hygiene conditions. ${ }^{7,8}$

Even though food intolerance (vomiting, abdominal bloating, diarrhea, or gastric retention) is frequent in the feeding process of preterm infants, ${ }^{9,10}$ it is difficult to prove whether breast milk bacterial contamination is the cause of such intolerance because there are many other factors that might have an impact on this event. 
Quite often mothers of preterm infants who are admitted to the neonatal intensive care units (NICU) are at home while their babies are hospitalized, therefore milk sometimes is expressed somewhere else rather than in the healthcare facility. Precautions are necessary to prevent contamination; it is quite likely that expressing breast milk at home, where there is less control, will result in a more significant contamination than doing it at the healthcare facility.

The objective of this study was to compare the degree of contamination of breast milk expressed at a healthcare facility versus at home.

\section{POPULATION, MATERIAL AND METHODS}

A cross-sectional study was performed to test breast milk samples obtained from mothers of newborn infants with $\leq 35$ weeks of gestational age who received enteral feeding between April 17, 2009 and January 6, 2011. All mothers of hospitalized preterm infants were included; breast milk samples from mothers with infectious conditions considered a contraindication to breastfeeding or who used illegal drugs or medications not allowed during breastfeeding were excluded.

Newborn infant status: in all cases the gestational age, birth weight, and presence of food intolerance (vomiting, abdominal bloating, diarrhea or gastric retention $\geq 25 \%$ of the volume) or necrotizing enterocolitis were recorded.

Breast milk samples: pairs of breast milk expressed at home or at the NICU on the same day were obtained. Instructions describing all the procedures related to milk expression were provided together with a sterilized bottle and a thermal bag for storage and transportation. Milk expressed at the breast pumping room in the NICU was obtained via an aseptic technique with an electrical pump, a milk pump sterilized in steam during 90 minutes and with simple packing, hair tied back, no jewelry, rolled up sleeves and hands washed with liquid soap before milk expression.

Though breast milk could be expressed at home manually or with a milk pump, all mothers used a milk pump and transported the milk to the healthcare facility in a sterilized bottle inside an insulated container, packed in ice. Milk expression procedures were different at the healthcare facility in comparison to procedures used at home because the former were monitored following the standard hospital procedures while at home it was not, as it happens in "real life". Date of expression, sample temperature, volume and appearance were recorded in all the cases. All samples were stored at $4{ }^{\circ} \mathrm{C}$ until the time of processing (less than 8 hours) performed in the Microbiology Laboratory (School of Pharmacy and Biochemistry, Universidad de Buenos Aires) by staff blinded at their origin (expressed at home or at the healthcare facility).

Case selection: samples were collected once a week due to operative reasons. In order to ensure their representatation, the day of each week in which collection would take place was determined $a$ priori based on a table of random numbers (by assigning a consecutive number from 1 to 5 ). On each selected day, a couple of milk samples were collected from each participating mother (one previously expressed at home and the other one at the healthcare facility). All those mothers who met the inclusion criteria accepted to participate in the study.

Microbiological screening: for the purpose of this study, a milk sample that had more than $10^{5}$ $\mathrm{CFU} / \mathrm{mL}$ of mesophilic aerobic bacteria, ${ }^{6}$ presence of Escherichia coli, enterobacteria, Staphylococcus aureus, Streptococcus faecalis, Pseudomonas, Salmonella or fungi was considered to be contaminated.

Microbiological test: quantitative tests of mesophilic aerobic bacteria, fungi and yeast count, and enterobacteria count were done as indicators of microbiological safety, as well as the examination in $1 \mathrm{~mL}$ of milk of species of Salmonella, coliforms, Escherichia coli, Staphylococcus aureus, Pseudomonas aeruginosa and Burkholderia cepacia.

Mesophilic aerobic count: it was done by deepseeding in Plate Count Agar (PCA), by adding $0.1 \%$ of skimmed milk powder, and incubated during 48 hours at $35^{\circ} \mathrm{C}$.

Fungi and yeast count: it was performed by deep-seeding in Yeast Extract Glucose Chloramphenicol (YGC) agar plates, and incubated during 5 days at $25^{\circ} \mathrm{C}$.

Enterobacteria count: it was performed by deep-seeding in Violet Red Bile Glucose Agar (VRBGA) plates, and incubated during 24 days at $35^{\circ} \mathrm{C}$.

Testing for E. coli and coliforms: $1 \mathrm{~mL}$ of milk was incubated during $24 / 48$ hours at $35^{\circ} \mathrm{C}$ in lactose broth. After this period of enrichment, it was inoculated in a hooded tube that contained bright green broth; in those tubes that presented growth (turbidity and gas), an isolation on chromogenic agar was done to confirm E. coli and coliforms.

Testing for Salmonella: from the lactose broth, two tubes were seeded, one with RappaportVassiliadis broth and one with tetrationate broth, which were incubated during 24 hours at $35^{\circ} \mathrm{C}$ 
and then isolated on xylose-lysine-desoxycholate (XLD) and bismuth-sulfite (BS) agar plate surfaces. In case of yielding typical colonies, biochemical tests with API 20E were done.

Testing for Staphylococcus aureus: $1 \mathrm{~mL}$ of breast milk was incubated during $24 / 48$ hours at $35^{\circ} \mathrm{C}$ in trypticase soy broth (TSB), after this period of enrichment it was isolated on the surface of Baird-Parker agar $\left(35^{\circ} \mathrm{C}, 48\right.$ hours). Typical colonies were confirmed by API STAPH and coagulase production.

Testing for Pseudomonas aeruginosa: from the TSB enriched broth, isolation was performed on the surface of cetrimide agar $\left(35^{\circ} \mathrm{C}\right.$ during 48 hours); typical colonies were confirmed by API 20NE.

Testing for Burkholderiacepacia: from the TSB enriched broth, isolation was performed on the surface of $\mathrm{BCsA}$ agar $\left(35^{\circ} \mathrm{C}\right.$ during 48 hours); typical colonies were confirmed by API 20NE.

Ethical considerations: the study was approved by the Ethics Committee and the Teaching and Research Committee of the healthcare facility. The informed consent of all participants was requested and obtained.

Each newborn infant was fed with breast milk of his/her own mother. When bacterial overgrowth was confirmed, the mother was instructed to improve the technique for breast milk expression and transportation. Authors have no conflict of interest to disclose.

Statistical Analysis: assuming that the contamination of breast milk obtained at the healthcare facility can reach $15 \%$ and twice as much when expressed at home and that in up to $5 \%$ of the cases the mother might choose not to participate or the case might not be evaluable, 280 cases (140 pairs) are required to verify this difference with a $95 \%$ confidence interval and a power of $80 \%$.
The frequency of categorical variables is described by percentages with their $95 \%$ confidence intervals. The association between the contamination and the source of the breast milk was evaluated with a $\chi^{2}$ test, assuming a two tailed $p<0.05$ significance level; the OR was estimated with its corresponding $95 \%$ confidence intervals.

\section{RESULTS}

A total of 280 breast milk samples were collected and analyzed (140 pairs: one sample was obtained at home and the other one at the healthcare facility on the same day) from 53 mothers of hospitalized newborn infants. A breast milk pump was used to obtain all the samples at home. Given that a couple of samples were obtained per week until the time infants could be breastfed, 8 pairs of samples were obtained from 1 mother; 6 pairs from $2 ; 5$ pairs from $5 ; 4$ pairs from $5 ; 3$ pairs from 11; 2 pairs from 13; and only 1 pair from 16 mothers.

All patients were less than or equal to 35 weeks of gestational age and the average weight was $1484 \mathrm{~g}$ (ranging from $600 \mathrm{~g}$ to $2390 \mathrm{~g}$ ).

From the total of analyzed samples, 139 (49.6\%; 95\% CI: 43.6 to 55.6) were contaminated; and contamination was significantly more frequent in the samples obtained at home than those obtained at the healthcare facility $(59.6 \%$ versus $39.6 \% ; p=0.0008$; OR: $2.25 ; 95 \%$ CI: 1.36 to 3.7 ). The same was observed in relation to mesophilic bacteria, enterobacteria, and coliforms (Table 1).

The mothers of the 7 patients who had food intolerance during the hospitalization period contributed with 32 breast milk samples; the contamination rate observed was similar to that of mothers whose children did not have food intolerance $(53.1 \%$ versus $49.6 \%$; $p=0.7$; OR: $1.15 ; 95 \%$ CI: 0.52 to 2.56 ).

TABLE 1. Microbiological findings in 280 breast milk samples, according to the place where they were obtained

\begin{tabular}{|c|c|c|c|c|c|c|c|c|}
\hline \multirow[t]{2}{*}{ Microorganism } & \multicolumn{2}{|c|}{ Total } & \multicolumn{2}{|c|}{ Place where the sample was expressed } & \multirow[t]{2}{*}{$p^{*}$} & \multirow[t]{2}{*}{ OR } & \multicolumn{2}{|c|}{$95 \% \mathrm{CI}$} \\
\hline & $n$ & $\%$ & At home & At the healthcare facility & & & & \\
\hline \multicolumn{9}{|l|}{ Mesophilic aerobic } \\
\hline bacteria $>10^{5} \mathrm{CFU} / \mathrm{mL}$ & 109 & 39.2 & 68 & 41 & 0.001 & 2.23 & 1.3 & 3.7 \\
\hline Enterobacteria & 26 & 9.4 & 19 & 7 & 0.01 & 2.94 & 1.1 & 8.01 \\
\hline Coliforms & 41 & 14.7 & 28 & 13 & 0.01 & 2.4 & 1.1 & 5.1 \\
\hline E. coli & 12 & 4.3 & 7 & 5 & 0.5 & 1.4 & 0.4 & 5.2 \\
\hline Staphylococcus aureus & 22 & 7.9 & 12 & 10 & 0.6 & 1.2 & 0.4 & 3.1 \\
\hline Candida albicans & 6 & 2.2 & 3 & 3 & 0.9 & 0.99 & 0.1 & 6.2 \\
\hline
\end{tabular}

${ }^{*} \chi^{2}$ or Fisher's test, as appropriate.

More than one microorganism might grow in each sample. 


\section{DISCUSSION}

There is scarce information regarding the microbiological safety of breast milk expressed at home administered to a preterm infant who does not get fed by suction. In the United Kingdom it has been established that the bacterial growth should not be over $10^{5} \mathrm{CFU} / \mathrm{mL}$ before pasteurization; ${ }^{11}$ in Italy the level accepted is up to $10^{4} \mathrm{CFU} /$ $\mathrm{mL}$ or between $10^{4}$ and $10^{5}$, but if S. aureus. ${ }^{12}$ is not present; the Human Milk Banking Association of North America (HMBANA) requires that the expressed milk should have a count lower than $10^{4}$ $\mathrm{CFU} / \mathrm{mL}$ and the absence of pathogen bacteria; in Brazil breast milk is considered suitable for consumption if it has less than $2.5 \times 10^{3} \mathrm{CFU} / \mathrm{mL} .{ }^{13} \mathrm{In}$ the study by Novak et al. ${ }^{14}$ a count of $<10^{4} \mathrm{CFU} /$ $\mathrm{mL}$ is accepted for consumption of milk.

We found that, following the adopted definition, almost half the breast milk samples were contaminated, which was significantly higher in the samples collected at home. We recorded that almost $40 \%$ of the samples had a growth of mesophilic bacteria $\geq 10^{5} \mathrm{CFU} / \mathrm{mL}$ ( $29 \%$ if only samples obtained at the healthcare facility were considered).

Torres De Freitas, et al. ${ }^{15}$ found bacterial growth in all the samples with no less than $10^{2}$ $\mathrm{CFU} / \mathrm{mL}$, while Law, et al. ${ }^{16}$ found $\leq 10^{8} \mathrm{CFU} /$ $\mathrm{mL}$ in $25 \%$ of their samples, and Dardes ${ }^{7}$ verified growth of mesophilic bacteria lower than 2500 $\mathrm{CFU} / \mathrm{mL}$ in $80 \%$ of the analyzed samples. These differences in the way of expressing tolerable levels of bacterial growth clearly reflect the lack of consensus about an acceptable level in breast milk.

In relation to microorganisms considered especially pathogenic (enterobacteria, coliforms, Staphylococcus), they were seen in $38.2 \%$ of samples, similar to whatwas reported by Dardes, et al. ${ }^{7}(34.4 \%)$.

Additionally, yeast and fungi growth would indicate inadequate hygienic and sanitary conditions, especially due to the incorrect washing of hands. In our study Candida albicans was found in 6 samples $(2.14 \%)$, while Serafini ${ }^{8}$ identified it in $22 \%$ of the samples.

The greatest contamination of samples collected at home could be due to the method used to express milk or to transportation conditions.

Though mothers were instructed in the use of the adequate technique and a weekly reminder was put in place, there was no control of the procedures used at home, while in the healthcare facility they were directly supervised by a trained nurse and carried out in an area prepared to this end. Additionally, the recommendation to throw away the first milliliters of expressed breast milk before collecting it was included in the instructions; this measure helps decrease up to $90 \%$ of bacterial population. ${ }^{13}$ Although the level of understanding of instructions was not evaluated nor the possible impact of the "learning effect" (18 mothers provided 4 or more samples, accounting for almost half of the samples), all participants said they had understood instructions, and all the samples were adequately sent.

Even though this might seem reasonable, there is no evidence that suggests a relationship between bacterial overgrowth in the expressed breast milk and feed intolerance in the preterm infant. ${ }^{16,17}$ Our analysis was exclusively exploratory. The design of the study did not allow to establish the relationship between bacterial contamination of the breast milk administered and food intolerance, necrotizing enterocolitis or other infectious diseases. This relationship should be analyzed by means of studies designed to this end.

If it is necessary to resort to breast milk expressed at home, measures to guarantee the adequate breast milk expression and transportation should be maximized. In the light of the evidence available, fresh breast milk expressed with the adequate techniques is still the best option to feed preterm newborn infants.

\section{CONCLUSION}

Half of the breast milk samples had bacterial growth, which was more frequent in the samples obtained at home than in the healthcare facility.

\section{BIBLIOGRAPHY}

1. Llanos A, Mena P, Uauy R. Tendencias actuales en la nutrición del recién nacido prematuro. Rev Chil Pediatr 2004;75(2):107-21.

2. Macías S, Rodríguez S, Ronayne de Ferrer P. Leche materna: composición y factores condicionantes de la lactancia. Arch Argent Pediatr 2006;104(5):423-30.

3. Martin R, Langa S, Reviriego C, Jiménez, Marín M, et al. The comensalmicroflora of human milk: new perspectives for food bacteriotherapy and probiotics. Trends Food Sci Technol 2004;15:121-7.

4. McGuire W, Henderson G, Fowlie PW. Feeding the preterm infant. BMJ 2004;329:1227-30.

5. National Institute for Health and Clinical Excellence. NICE clinical guideline. 93 Donor breast milk bank: the operation of donor milk banks services. [Accessed:03/22/2012]. Available at: http://www.nice.org.uk/nicemedia/pdf/ CG93FullGuideline.pdf.

6. Farmacopea Nacional Argentina ( $8^{\mathrm{a}}$ ed.). Control higiénico de productos no obligatoriamente estériles. [Accessed: 03/26/2012]. Available at: http:/ /www.anmat.gov.ar/we- 
banmat/fna/octava_edicion/Primer_Volumen.pdf.

7. Dardes de Almeida C, Rozolen C, GoulartA, Kopelman B. Is Breast Milk Collected at Home Suitable for Raw Consumption by Neonates in Brazilian Public Neonatal Intensive Care Units? J Hum Lact 2006;22:418-25.

8. Serafini A, André M, Rodrígues M, Kipnis A, Carvalho C, ET al. Microbiological quality of human milk from a Brazilian milk bank. Rev Saude Publica 2003;37(6):775-9.

9. Martínez Ferro M, Cannizzaro C, Rodriguez S, Rabasa C. Neonatología Quirúrgica. Buenos Aires: GrupoGuía; 2004.

10. Springer S, Annibale D. Necrotizing enterocolitis. [Accessed:03/22/2012]. Available at: http:/ / emedicine.medscape.com/article/977956-overview.

11. Balmer S, Williams A. Guidelines for the establishment and operation of human milk banks in the UK. Arch Dis Child 1995;73(5):481-2.

12. De Nisi G, Ambruzzi AM, Arslanoglu S, Bertino E, Biasini A, et al. Linee Guida per la costituzione e l'organizzazione di una Banca del Latte Umano Donato. Società Italiana di Neonatologia. 2da edizione. New Magazine Edizioni. Trento, 2007. [Accessed: 03/22/2012]. Available at: www. aiblud.org/file/BLUD.PDF.
13. Normas técnicas para Bancos de LecheHumana-Red BLHBrasil-RECOLECCIÓN-BLH-IFF/NT-16.04-Ordeñe:Procedimientos Higiénico-Sanitarios [Accessed:18/10/2012]. Available at: http://www.fiocruz.br/redeblh/media/coletaesp.pdf.

14. Novak F, Da Silva A, Hagler N, Figueiredo A. Contamination of expressed human breast milk with an epidemic multiresistant Staphylococcus aureus clone. J Med Microbiol 2000;49:1109-17.

15. Torres De Freitas A, Duran Z, Rodriguez C. Acidez titulable como control de calidad para la leche humana. Arch Venez Pueri Pediatr 2009;73:92-6.

16. Law BJ, Urias BA, Lertzman J, Robson D, Romance L. Is ingestion of milk-associated bacteria by premature infants fed raw human milk controlled by routine bacteriologic screening? J Clin Microbiol 1989;27(7):1560-6.

17. Schanler R, Fraley J, Lau C, Hurst N, Horvath L, Rossmann $\mathrm{S}$. Breast milk cultures and infection in extremely premature infants. J Perinatol 2011;31(5):335-8.

18. de Silva A, Jones PW, Spencer SA. Does human milk reduce infection rates in preterm infants? A systematic review. Arch Dis Child Fetal Neonatal Ed 2004;89(6):F509-13. 


\section{ANNEX}

\section{Instructions to express milk from your breast at home}

- Choose a quiet, relaxing area, away from distractions.

- Wash your hands with water and white soap by rubbing during 10 seconds. Rinse them with abundant water and dry well with disposable paper. Spread alcohol gel on your hands.

- Clean your nipples with water and soap, rinse them by using a dressing soaked in saline solution, dry them with a clean dressing.

- Throw away the first milliliters of expressed breast milk.

- Express the breast milk immediately before going to the healthcare facility.

\section{Hand expression of breast milk}

- Put the hand on the breast, forming the letter " $\mathrm{C}$ ", and positioning the thumb on the upper part of the breast, about $3 \mathrm{~cm}$ above the nipple. The palm of the hand is positioned on the lower part of the breast.

- Do a milking movement, that is to say, rub the breast backwards (as if sinking the breast) and forwards, while pressing, as if you wanted to join your fingers together. With this movement you should feel that not only the skin but that all the mammary tissue is moving.

- Repeat the movement slowly and rhythmically. If it is comfortable for you, it is better to alternate breasts every 5 to 10 minutes.

- Hold the container with the opposite hand.

\section{Expressing breast milk with a breast pump}

- Use detergent to wash all pieces of the breast pump and boil in water during 15 minutes. Dry them with disposable paper.

\section{Storage}

- Store the expressed milk in a sterilized bottle with a label (baby's name and surname, time and day breast milk was extracted). Once the bottle is closed it should not be opened.

- Keep the bottle in the refrigerator (neither in the freezer unit nor in the freezer compartment) and separated from food.

\section{Transportation}

- To transport the expressed breast milk, withdraw the bottles from the refrigerator and place them in the thermal bag before going to the healthcare facility. 